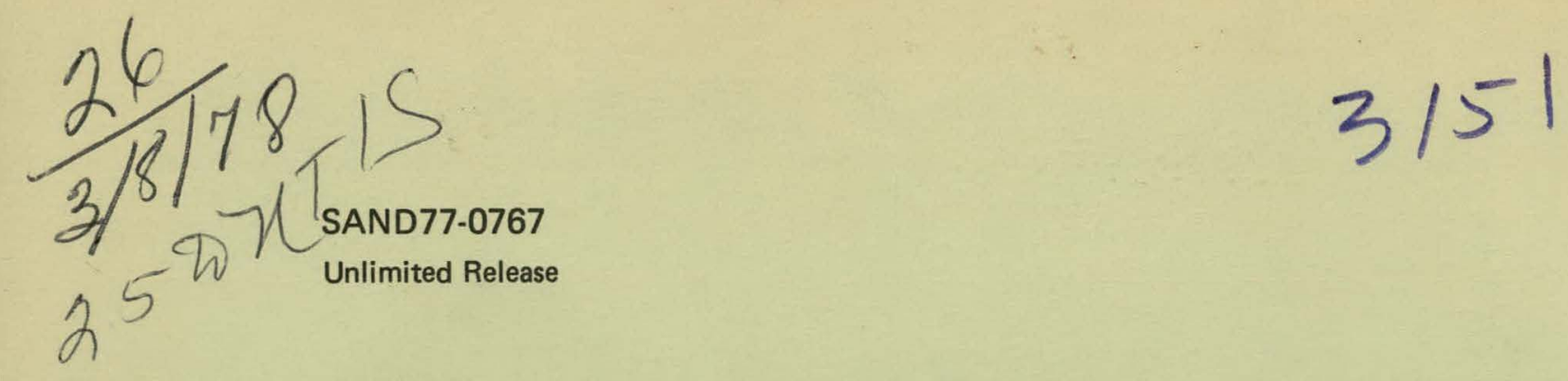

\title{
MISTER
}

\section{Sandia Laboratories Technical Capabilities:}

\section{COMPUTATION SYSTEMS}

Prepared by Sandia Laboratories, Albuquerque, New Mexico 87115 and Livermore, California 94550 for the United States Department of Energy under Contract AT(29-1)-789

Printed December 1977

Supersedes SAND74-0080 


\section{DISCLAIMER}

This report was prepared as an account of work sponsored by an agency of the United States Government. Neither the United States Government nor any agency Thereof, nor any of their employees, makes any warranty, express or implied, or assumes any legal liability or responsibility for the accuracy, completeness, or usefulness of any information, apparatus, product, or process disclosed, or represents that its use would not infringe privately owned rights. Reference herein to any specific commercial product, process, or service by trade name, trademark, manufacturer, or otherwise does not necessarily constitute or imply its endorsement, recommendation, or favoring by the United States Government or any agency thereof. The views and opinions of authors expressed herein do not necessarily state or reflect those of the United States Government or any agency thereof. 


\section{DISCLAIMER}

Portions of this document may be illegible in electronic image products. Images are produced from the best available original document. 
Issued by Sandia Laboratories, operated for the United States Department of Energy by Sandia Corporation.

\section{NOTICE}

This report was prepared as an account of work sponsored by the United States Government. Neither the United States nor the United States Department of Energy, nor any of their employees, nor any of their contractors, subcontractors, or their employees, makes any warranty, express or implied, or assumes any legal liability or responsibility for the accuracy, completeness or usefulness of any information, apparatus, product or process disclosed, or represents that its use would not infringe privately owned rights.

Printed in the United States of America

Available from

National Technical Information Service

U. S. Department of Commerce

5285 Port Royal Road

Springfield, VA 22161

Price: Printed Copy $\$ 4.50 ;$ Microfiche $\$ 3.00$ 
SAND77-0767

Unlimited Release

Printed December 1977

Supersedes SAND74-0080

\title{
SANDIA LABBORATORIES TECHNICAL CAPABILITIES :
}

\section{COMPUTATION SYSTEMS}

\begin{abstract}
This report characterizes the computation systems capabilities at Sandia Laboratories. Selected applications of these capabilities are presented to illustrate the extent to which they can be applied in research and development programs.
\end{abstract}

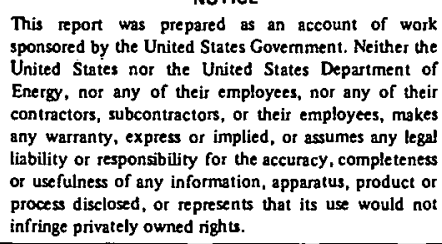




\section{FOREWORD}

Sandia Laboratories, a multiprogram laboratory of the Department of Energy, is located in Albuquerque, New Mexico, and Livermore. California, with a remote testing facility at Tonopah, Nevada. In fulfilling its responsibilities in the fields of national security and energy, and in other programs, Sandia has acquired extensive capabilities in research, development, testing, and evaluation, and has made numerous contributions in scientific and engineering fields. These capabilities-the basic tools used in research and development-are the subjects of this series of reports. Each of these capabilities is described in a separate report, as listed below. In each report supporting information is provided to show applications of the capabilities.

All the capabilities are in current use. It is intended that their descriptions will allow planners to directly associate them with the technical requirements of studies being considered, and that they will also be sources of technical information for other laboratories, federal agencies, universities, and the Sandia staff.

For those interested in the overall capabilities of the Laboratories, all the reports are compiled in a single publication bearing its own number.

C. Donald Lundergan, Technical Editor

P. L. Mead, Publication Editor .

TECHNICAL CAPABILITIES OF SANDIA LABORATORIES

\begin{tabular}{|c|c|c|c|}
\hline & & $\begin{array}{l}\text { mary } \\
77-0651)\end{array}$ & \\
\hline $\begin{array}{l}\text { Aerosciences } \\
\text { Applied Mathernatics } \\
\text { Biosciences } \\
\text { Computation Systems } \\
\text { Design Definition and } \\
\text { Fabrication } \\
\text { Earth Sciences } \\
\text { Electronics } \\
\text { Engineering Analysis } \\
\text { Explosives, Electrochemistry, } \\
\text { and Electromechanisms }\end{array}$ & $\begin{array}{l}\text { SAND74-0075 } \\
\text { SAND74-0079 } \\
\text { SAND74-0076 } \\
\text { SAND77-0767 } \\
\text { SAND76-0413 } \\
\text { SAND74-0085 } \\
\text { SAND74-0086 } \\
\text { SAND'4-0U81 } \\
\text { SAND74-0081 }\end{array}$ & $\begin{array}{l}\text { Instrumentation and Data Systems } \\
\text { Materials and Processes } \\
\text { Measurement Standards } \\
\text { Physical Sciences } \\
\text { Quality Assurance } \\
\text { Safety and Reliability Assurance } \\
\text { Systems Analysis } \\
\text { Testing } \\
\text { Auxiliary Capabilities } \\
\text { Environmental Health } \\
\text { Information Sciences }\end{array}$ & $\begin{array}{l}\text { SAND74-0083 } \\
\text { SAND77-0002A } \\
\text { SAND74-0077 } \\
\text { SAND74-0074 } \\
\text { SAND77-0652 } \\
\text { SAND74-0090 } \\
\text { SAND74-0089 } \\
\text { SAND74-0088 } \\
\text { SAND74-0082 }\end{array}$ \\
\hline
\end{tabular}




\title{
COMPUTATION SYSTEMS*
}

The computing centers and their technical support organizations at Sandia Albuquerque and Sandia Livermore are responsible for planning, adapting, and operating large-scale digital computer facilities in support of the scientific and engineering community of the Laboratories. Such modern, large-scale computers are essential to the solution of such problems as component design and development, modeling of complex systems, and detailed simulation of physical phenomena. A growing number of smaller digital computers are being integrated in to facilities dedicated to the support of specific areas of research and development such as experiment control, data acquisition, and test monitoring. A few main-line computers are also devoted to management information and business data processing, but as these are nontechnical functions, they are not covered in detail in this report. The major example is the dual-processor Univac 1108 system, which is primarily devoted to administrative computing, although about $25 \%$ of its time is used for engineering support in such-areas as quality control; engineering information, and product inventory.

The central computing facilities are based on Control Data Corporation scientific computer systems. The Albuquerque facility contains three CDC-6600's and a CYBER-172 which share a common mass-storage subsystem as well as extended core storage. The latter computer functions as a front-end controller in support of the largest computer in the complex, a CDC7600. The Livermore facility contains two CDC-6600's, also with a common mass storage capability and a shared extended core. Remote job entry and interactive computation are increasingly emphasized. Time-sharing is accommodated at both centers. At Albuquerque, one of the CDC-6600's is devoted exclusively to the support of time-sharing activities during the normal workday.

\author{
A. R. Iacoletti \\ Technical Coordinator
}

\section{Computation Systems Professional Staff and Investment in Equipment}

\begin{tabular}{|c|c|c|}
\hline & $\begin{array}{l}\text { Professional } \\
\text { Staff } \\
\end{array}$ & $\begin{array}{c}\text { Investment } \\
\text { in Equipment } \\
\text { (in } \$ 1000) \\
\end{array}$ \\
\hline $\begin{array}{l}\text { Central Computer Systems and } \\
\text { Associated Technical Support }\end{array}$ & 143 & 33,500 \\
\hline Computer Center Support Staffs & 86 & \\
\hline Corresponding Line Support Staffs & 57 & \\
\hline $\begin{array}{l}\text { Major Computer-Based Special-Purpose } \\
\text { Systems and Support }\end{array}$ & 44 & 6,000 \\
\hline
\end{tabular}

*Compiled November 1977 


\section{SYSTEM PLANNING, DEVELOPMENT, AND SUPPORT}

These services are provided (1) to perform the long-range planning required for future computing systems, (2) to assemble and adapt computer facilities for the needs of the Laboratories, and (3) to determine and promulgate ways to use existing facilities most effectively. These activities encompass the evaluation of computer technology and its projection in the context of the evolving needs of the Laboratories, the adaptation and development of software for operating systems, the construction of software for specific applications, computer hardware specification and selection, mathematical services, communications, and consultation.

\section{Computer System Support}

Activities are directed toward the development and adaptation of computer facilities to meet evolving computing needs in the scientific and engineering areas. Recent emphasis has been in interactive computation, multicomputer networking, and remote entry. Specific developments have included the design and implementation of software systems permitting concurrent, multimachine access to a common, on-line mass-storage facility. Development of the existing Sandia Interactive Graphics System (SIGS) is another example. (Items $1-3^{*}$ )

\section{Current Activities}

Multicomputer network design and development Computer configuration structuring and selection System development for special-application computers

Computer interface hardware design

Front-end processor for remote job entry

File management software development

Operating systems and compiler support

Simulation of computer systems

Remote plotting network development

\section{Mathematical Computing Support Services}

Activities include mathematical modeling, numerical analysis and code construction relative to specific research and development problems or problem classes, as well as the development of generalized mathematical. subroutines for broad use in numerous application codes. These subroutines collectively constitute the Sandia Mathematical . Program Library: (Items 4:9)

\footnotetext{
*See Highlights, below.
}

\section{Current Activities}

Applied mathematics and numerical analysis support services

Mathematical program subroutine library development and updating

Numerical analysis research

Aerodynamic/ablation codes

Fluid mechanics and heat-transfer analysis

Generalized mesh generation for structural analysis computations

Statistical signal-processing studies

Field-test analysis support

Computer benchmarking studies (test codes for evaluating new equipment)

Nuclear waste disposal

Combustion research

\section{Consultation Support}

These efforts include the collection and distribution of information bearing on effective use of computing facilities. In addition, a continuing program of technical training and consultation is conducted for the user community.

\section{Current Activities}

Computing course development

User consultation services

Programming manual preparation

Video taping of computer courses and symposia

Computing newsletters

Computer-operator training

Corporate contact for inter-laboratory code distribution

Maintenapoe of general uce program abctraats and computing library

Code-improvement assistance 


\section{COMPUTATION SYSTEMS}

\section{SYSTEM PLANNING, DEVELOPMENT, AND SUPPORT}

\section{Communication Development and Support}

Activities include the development of communication links to support distributed processors, remote job entry terminals, and interactive user terminals, which are located throughout the Laboratories. These efforts provide the user with faster and easier access to the central computing facility.

\section{Current Activities}

Development of comprehensive laboratory communication plan

Minicomputer network development

Hardware design for computer complex

Maintenance and expansion of existing communication system

TV computer status system

Link to Sandia Livermore

Link to Los Alamos Scientific Laboratory

Link to other DOE laboratories

Item 1. Scientific Computer Network at Albuquerque (Figure I)

Operating system software has been developed to allow the sharing of mass storage by three CDC-6600's and a CDC CYBER-172. Sharing permits more effective use of computer resources and provides better service. It eliminates redundant copies of program and data files, significantly reduces the use of magnetic tapes, and provides fast access to files.

Common input/output queue software further extends the utility of the network. Common-queue software allows a job submitted to a remote entry station to be executed on whichever machine has the greatest facility for timely turnaround of that job. The common-queue package has sufficient safeguards to preserve queued files during virtually any type of system interruption.

Interactive graphics software permits simultaneous access to the network for up to 8 high-precision stations, each of which is connected to the central facility via a 40.8 kilobit-per-second link.

\section{Item 2. Dual CDC-6600 Complex at Livermore (Figure 2)}

The dual CDC- 6600 complex at Livermore provides access to a common mass-storage subsystem for both interactive and batch programs. For large codes, users may view input and output data interactively whereas the program itself is run in the batch mode, thus suiting the mode of operation to the application.

\section{Item 3. Further Development at Albuquerque}

The integrated computational network is being expanded. One phase of thic expansion is full integration of the CDC-7600 computer into the network. This will permit more efficient transfer of jobs into the computer and the use by those jobs of a shared catalogued file base. The file base will also be shared between the time-sharing node and the remainder of the network. This sharing will permit the construction and submittal of large batch jobs from a time-sharing terminal; the output of these jobs may later be scanned in an interactive mode. The remote job entry facility is also being expanded. Replacement of the preserıl. hardwired multiplexer will permit expansion of batch terminals from the present mix of 4 high-speed and 7 low-speed terminals to 8 high-speed and 20 low-speed terminals. The first phase of the expansion also calls for the implementation of electrostatic plotters at high-speed terminals. 


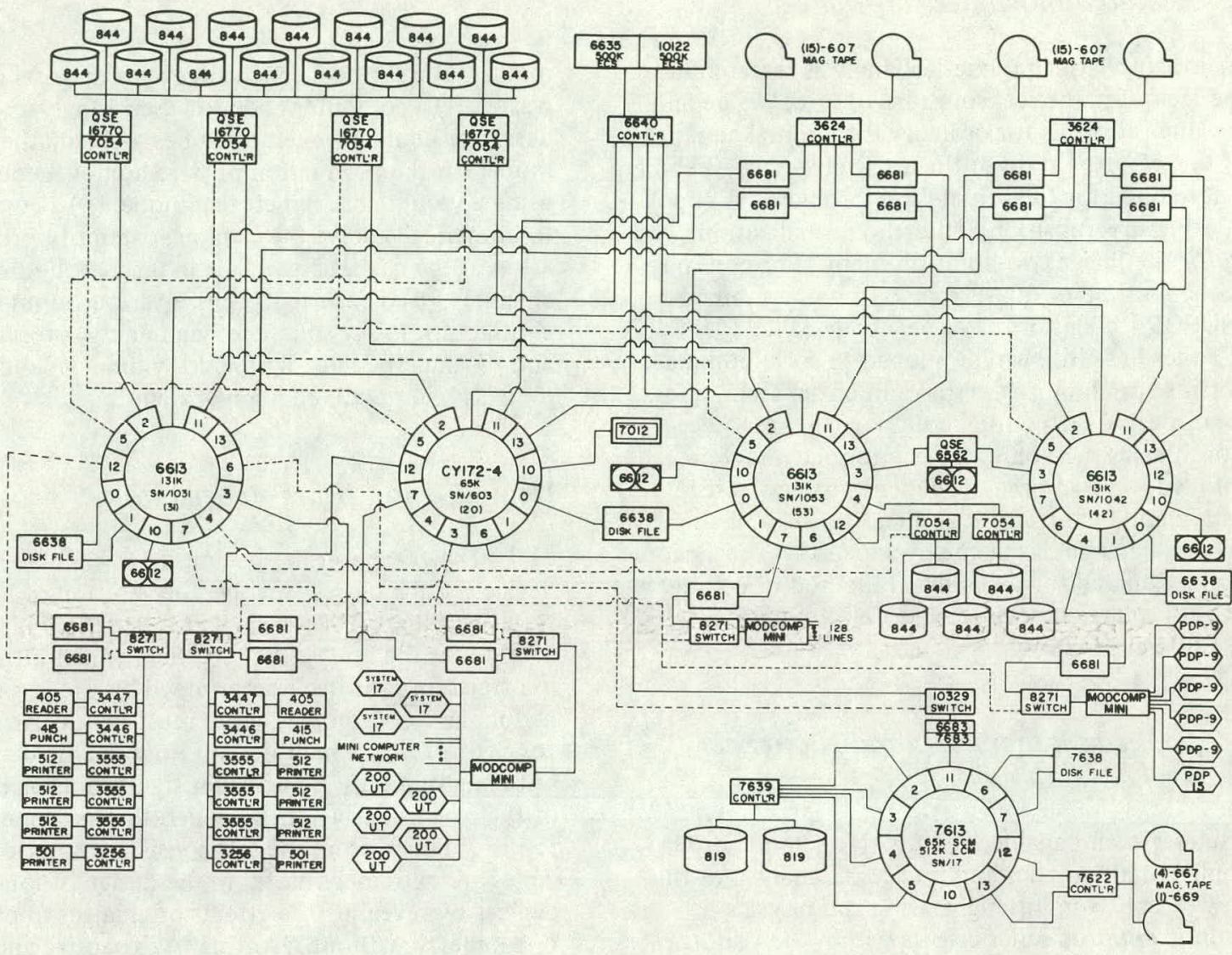

Figure 1. Scientific Computing Network at Sandia Albuquerque

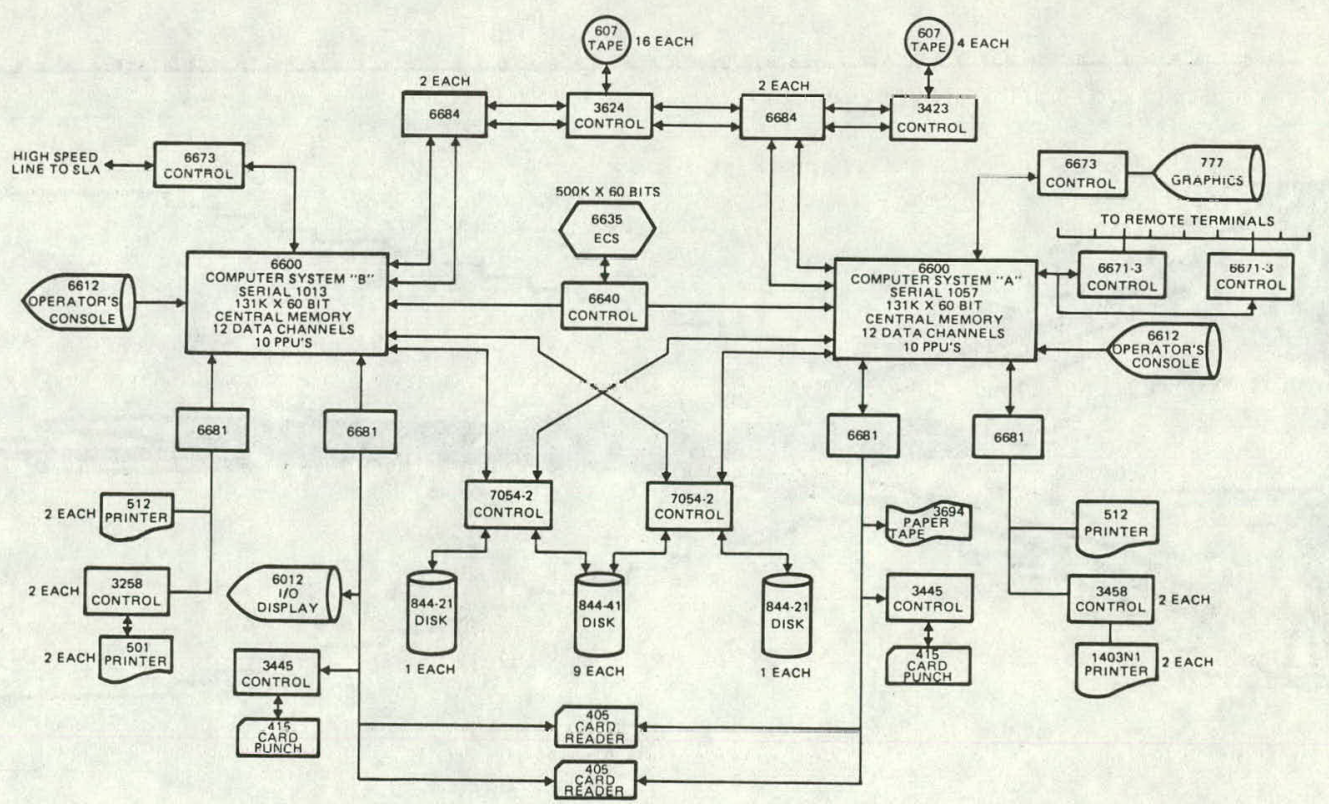

Figure 2. Dual CDC-6600 Complex at Gandia Livermore 
Item 4. Research in Numerical Analysis

A major emphasis in numerical analysis research has been in the area of numerical solutions of initial-value and boundary-value problems for ordinary differential equations. As part of this effort, a state-of-the-art Runge-Kutta-Fehlberg code was developed for the initial-value problem. A code, SUPORT, using superposition and orthonormalization, was developed for the linear two-point problem. For nonlinear problems, the method of quasilinearization is combined with the SUPORT code to form a new code called SUPORQ. A suite of codes has also been developed to solve boundaryvalue problems via "shooting" (trial and error) techniques. In the area of partial differential equations, a method-oflines approach using a B-spline collocation technique is being employed to solve time-dependent problems arising in combustion and heat-transfer studies. In the area of linear equations, a code has been developed that uses incomplete factorization and the generalized method of conjugate gradients to solve large sparse positive definite matrices that arise from finite-element models.

Item 5. Applied Mathematics and Numerical Analysis Support

Consultation and analysis are provided in numerous areas of applied mathematics and numerical analysis as they relate to a wide spectrum of engineering and physics problems. In support of other efforts within the Laboratories, the mathematical computing staff has recently developed (1) an interactive code, IUNFLD, to solve integral equations of the first or second kind and to use splines or polynomials for constrained curve fitting, (2) a mathematical model for the deep sea disposal of nuclear waste, (3) a computer code for use in analysis of the design of neutron generator tubes, (4) a mathematical model for the production of pure homogeneous ingots using a vacuum arc remelt technique, (5) a computer code to numerically solve the nonlinear stability problem that arises at the gas/slag interface in magnetohydrodynamics channels, (6) a code to optimize various input-output configurations for solar and wind energy storagc devices, and (7) a mathematical model for time-dependent, onedimensional premixed laminar flames.

\section{Item 6. Ion-Beam Accelerator}

The computer has been used to simulate ion-beam devices. Such devices involve the solution of ion trajectories together with the electrostatic field which accelerates the ions. Since the field which influences the ion trajectories is itself determined by the ion flow in the region, an iteration procedure must be used to find the configuration in which the ion flow and field are given self-consistently. Of particular significance is the shape of the plasma surface from which the ions emerge. This too is obtained from the self-consistent solution. Such codes are extremely useful in the design of ion-beam devices by revealing the effects of changes in parameters or geometry without resorting to expensive and timeconsuming experimentation. They also provide insight into the interpretation of experimental data. Figure 3 illustrates contours of constant ion density obtained by using the code.

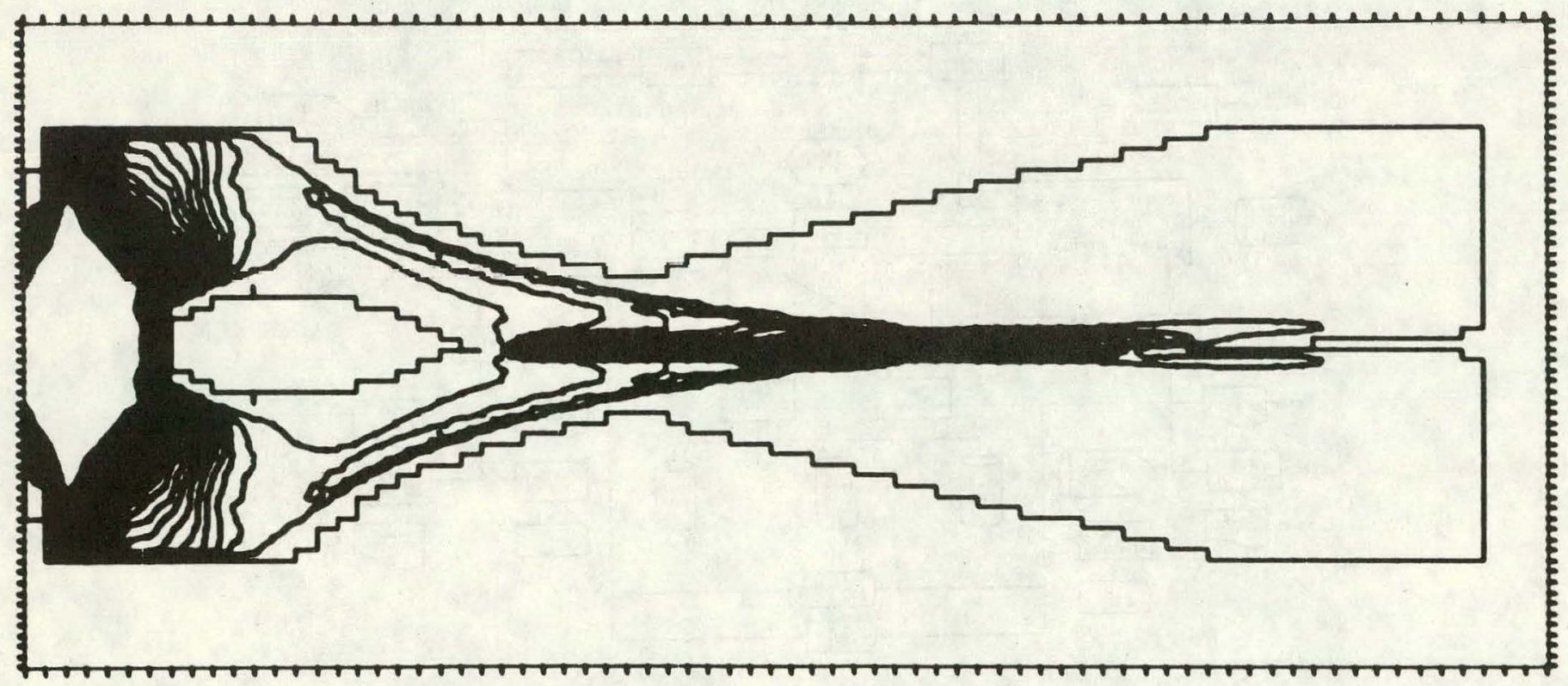

Figure 3. Contours of equal ion density 


\section{SYSTEM PLANNING, DEVELOPMENT, AND SUPPORT}

\section{Item 7. Mathematical Modeling of Alloy Solidification}

Alloy solidification studies related to the Sandia vacuum consumable arc remelt facility are being supported through development of a mathematical model of the molten-metal flow in the solidifying ingot. This model is now being used to develop a numerical simulation of the flow, incorporating phase changes, nonlinear material properties, and combined electromagnetic and buoyant body forces. The resulting code requires several novel features, including arbitrarily strained orthogonal coordinates and special operator splitting, so that the discrete equations will conserve energy, mass, and vorticity on grids of manageable size.

\section{Item 8. Solar Plant Simulation}

Evaluation of the costs and performance of solar and energy storage systems requires detailed computational simulations. One current program simulates the operation of solar electric plants in a utility network. Since solar energy may be collected at times when its use would not be optimal for the network, the simulation dispatches the solar units in a way that maximizes their value. The optimization involves such factors as minimizing the cost of fuel required to run conventional plants required as backup to insure that the network can reliably meet demand.

A Monte Carlo computer program (MIRVAL) simulating the sun-heliostat receiver interaction is used to generate power-versus-time input data for the dispatchingoptimization computation. Figure 4 shows the severe shadowing that would occur if a mirror field were used early in the morning.

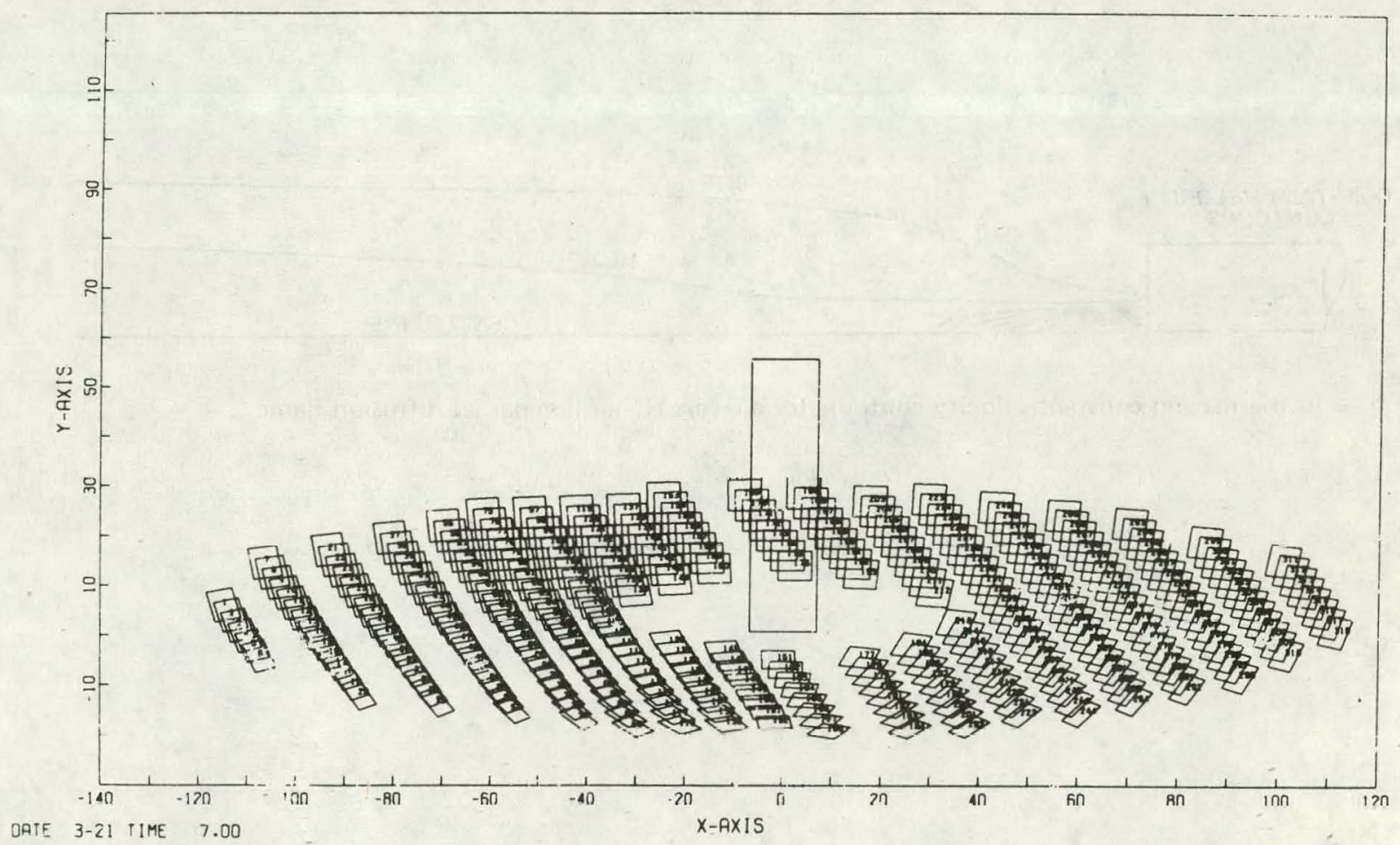

Figure 4. Mirror deployment and receiver tower for the solar test facility at Sandia Albuquerque, as viewed from the direction of the sun 


\section{Item 9. Combustion Modeling}

The modeling of multicomponent, chemically reacting fluid flows -- e.g., the description of physical phenomena involving combustion processes -- depends on the use of highspeed computers because of the complexity of the governing conservation equations. Presently, useful results are being obtained with both one-dimensional, time-dependent and two-dimensional, time-independent numerical models. Figure 5, an example of current work in the combustion field, shows the temperature and velocity contours for a steady-state hydrogen-air laminar jet diffusion flame. Other work in progess includes the numerical modeling of shielded diffusion flames, the prediction of specie and temperature histories of premixed laminar flames, computer simulation of chemically reacting fluid flows in porous media (weapon applications), and the development of detailed models for the study of engine cylinder flow fields.
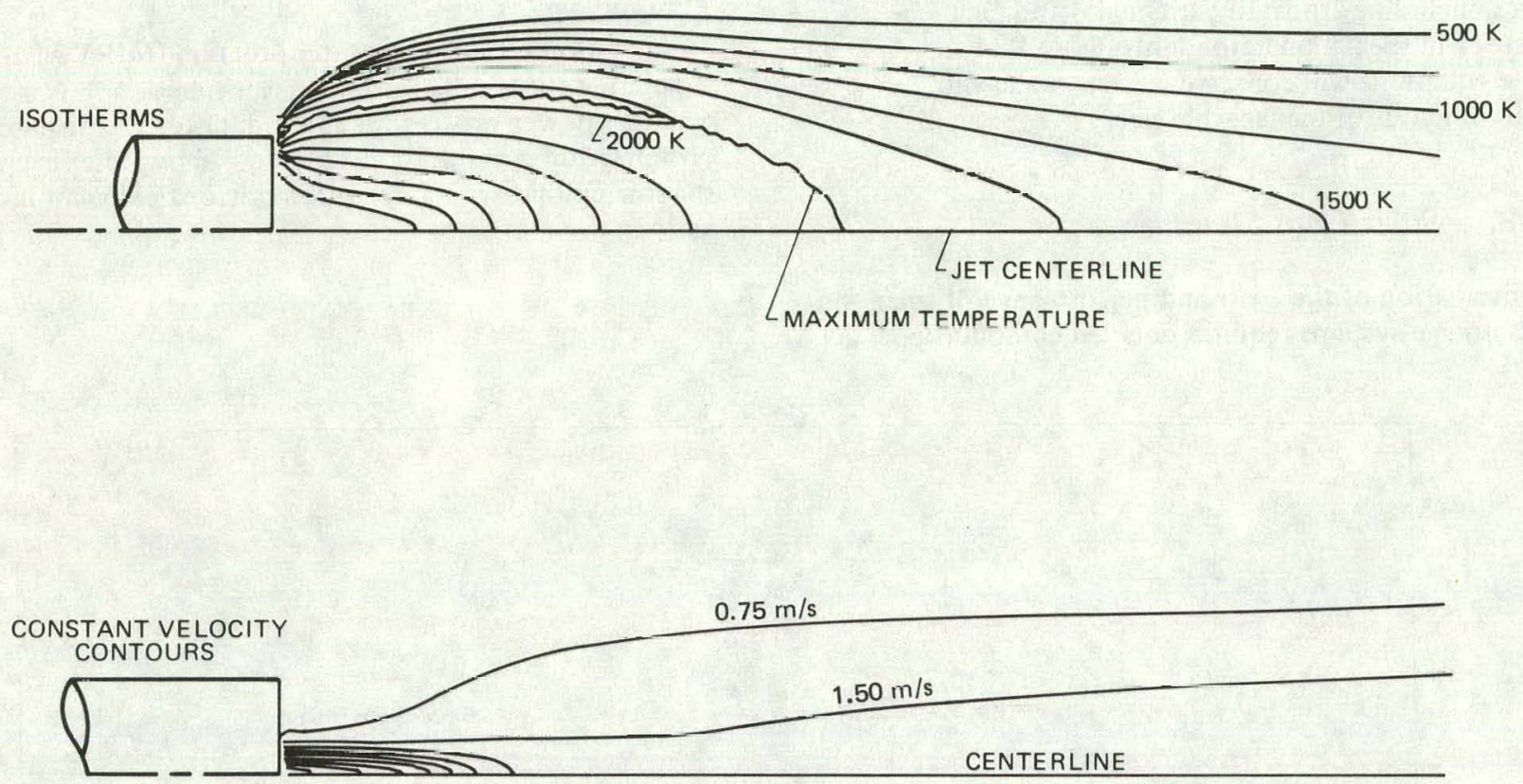

Figure 5. Isotherms and constant-velocity contours for a $6 \mathrm{~m} / \mathrm{s} \mathrm{H}_{2}$-air laminar jet diffusion flame 


\section{CENTRAL COMPUTING}

The central computing facilities at both the Albuquerque and Livermore locations of Sandia Laboratories are designed to accommodate the concurrent processing of a number of individual programs. Economies of scale are thus achieved by the effective sharing of high-performance central processors and centralized mass-storage file subsystems. Both batch and interactive modes of computation are supported. The bulk of the general-purpose computing load is handled by these main-line systems. This includes applications in the system studies area, as well as fundamental research, weapon design, reactor studies and nuclear safety, component development, effects modeling, and test-data reduction. The main-line systems at the centers are approved for the simultaneous processing of both unclassified and classified information, through Secret.

\section{Equipment}

Sandia's scientific computer systems are built ... " around CDC- 6600 and CD.C-7600 computers designed for high-speed extended precision calculations. The Albuquerque center contains three CDC-6600's and a CDC-7600 as worker computers, all sharing a common mass-storage subsystem. In addition, the three CDC-6600's share an extended core storage device (bulk core). These systems are accessed via a mixture of high and low-speed terminals. Interactive graphics applications are serviced by a network of six Digital Equipment Corporation computers (PDP-9's and a PDP. 15) remotely linked to one of the CDC-6600' 8 . A pair of Tektronix 4081 graphics stations and a large number of Tektronix 4014 and Tektronix 4010 storage tube terminals are also supported via the Time-Sharing System.

The Livermore computing center contains two CDC. 6600's sharing a common mass-storage subsystem. Extended core storage is also apportioned between the two machines. Also provided is a wide range of interactive graphics capabilities including (1) the CDC-777 Cybergraphics system, which consists of a CDC System 17 minicomputer controlling two high-capacity, highprecision graphics consoles remotely connected to one of the CDC-6600's; (2) a Tektronix 4081 graphics system which provides both refreshed and storage graphics and the ability to operate either as a stand-alone system or as an intelligent graphics terminal to a CDC6600 , and (3) a network of 10 Tektronix 4014 and 4010 graphics terminals for general time-sharing and graphics applications which do not require refresh capabilities.

Servicing the total scientific computing complex is an off-line computer output microfilm subsystem in the Albuquerque center consisting of a Datagraphix Model 4460 and a Model 4020. These devices can portray graphical information on $16 \mathrm{~mm} / 35 \mathrm{~mm}$ film and microfiche. Computer-generated motion pictures, in color or black-and-white, can be produced to represent time dependent physical processes:

Expansion of the computer output microfilm facility in Albuquerque is scheduled for the near future. This will include a microfilm recorder for reports and other tabular data, a graphical recorder with sufficient precision to accommodate the transcription of computergenerated E-size engineering drawings onto microfilm, and a graphical recorder for improved color film generation.

The Livermore center has installed an APPLICON AP-75 high-precision system to service the computer output microfilm requirements of that facility, including the generation of 16 and $35-\mathrm{mm}$ film and microfiche.

Current Major Equipment (Albuquerque)

\begin{tabular}{|c|c|}
\hline Computer Model or Feature & Number of Capacity \\
\hline CDC-7600 & 1 unit \\
\hline Small core memory & 65,000 words* \\
\hline Large core memory & 512,000 words * \\
\hline CDC- 6600 & 3 units \\
\hline $\begin{array}{l}\text { Main memory size } \\
\quad \text { (each) }\end{array}$ & 131,000 words" \\
\hline $\begin{array}{l}\text { Extended core storage } \\
\quad \text { (shared) }\end{array}$ & $1,500,000$ words* \\
\hline Shared mass storage & 367 million words* \\
\hline Nonshared mass storage & 259 million words* \\
\hline High-speed batch terminals & 3 units \\
\hline Low-speed batch terminals & 7 units \\
\hline High-performance graphics & 6 units \\
\hline
\end{tabular}

\footnotetext{
${ }^{*}$ Word size is 60 bits.
} 
Current Major Equipment (Livermore)

\author{
Computer Model or Feature \\ CDC-6600 \\ Main memory size \\ (each) \\ Peripheral-processors \\ (each) \\ Extended core storage \\ Shared mass storage \\ Nonshared mass storage \\ Graphics computer station \\ Interactive terminals
}

Number or Capacity

2

131,000 words*

10

500,000 words* 216 million words* 24 million words*

2

19
Mathematical libraries

Sandia mathematical program IMSL

Continuous system simulation languages CSSL MIMIC

Electronic circuit analysis ITRAC

ECAP SCEPTRE

NET

SPICE

SALOGS

"Word size is 60 hits.

\section{Programming Languages and Special Processors}

The central srientific computing facilities were acquired for the solution of problems in the research, design, development, and testing areas. Therefore, the programming languages, as well as the general-application software packages provided, are oriented toward this objective. FORTRAN is the primary language, although symbol manipulation, graphical plotting, simulation languages, and specialized higher-level software processors are also furnished. In contrast to the Laboratories' business data processing system (a dual processor UNIVAC-1 108), the emphasis has not been toward special languages for data-base management applications or other nonscientific activities.

Currently Supported Languages and Nationally Known Software Processors

Assemblers and compilers
COMPASS
FORTRAN extended
FORTRAN (FUN)
SNOBOL
PASCAL
ALGOL-60
Graphical plotting
DISSPLA
GCS
SCORS
IGS/44GO
SLPLOT
Maintenance Packages
UPDATE
MODIFY

Hcat transfer CINDA

Structural analysis NASTRAN

Spectral analysis MACRAN

\section{Mathematical Program Library}

The Sandia Mathematical Program Library consists of a number of FORTRAN-callable, high-quality, general-purpose mathematical subroutines. These, in turn, are incorporated in numerous individual computer programs that require the particular mathematical computations provided. Extensive validation testing, a standardized software approach, user-oriented documentation, and backup consultative support typify this capability. Numerical analysis research is carried out in conjunction with this effort. As numerical techniques evolve, state-ofthe-art improvements and/or replacements are made in the collection. This Library, although first implemented on the C.DC-6600's, has been developed with the objective of achieving a high degree of code portability.

\section{Current Routine Subcategories}

Linear algebraic equations

Numerical quadrature

Ordinary differential equations

Data fitting and smoothing

Eigenvalues and Eigenvectors of matrices

Fourier transforms

Zeros of functions and optimization

Zeros of polynomials

Special functions 


\section{TIME-SHARING SYSTEM}

A CDC- 6600 computer at the Albuquerque computing center and another at the Livermore center support Sandia's time-sharing requirements. Time-sharing is the nearly simultaneous servicing of many users interacting with the computer via keyboard and/or displaytube terminals. This mode of computation aids scientists and engineers in program design, information retrieval, and general problem-solving activities requiring rapid computer response and interactive control. Problems requiring long periods of computer time are executed on the batch computers (the CDC-7600 and the CDC-6600's): In Albuquerque the time-sharing system may be used to build and submit these longer-running jobs to the batch machines. Access to the system is via dial-up lines. Because these lines tie into the commercial telephone network, the time-sharing system is restricted to unclassified jobs. Access is controlled through user identifiers and passwords. Over 80 terminal users can be serviced concurrently. The Livermore center provides a comparable capability, but classified information can be handled there because the computer lines are hardwired.

\section{Equipment}

The CDC-6600 time-sharing facility in Albuquerque is configured to provide optimal service for its highly interactive load. Interactive use of the system involves such things as the editing of information, short program execution, and graphic data display. In this type of problem solving, the user expects prompt response from the computer. To provide adequate concurrent service, the system must have well-structured memory resources. The storage hierarchy in the CDC- 6600 system consists of a main memory, a high-speed extended core storage, and random-access magnetic-disk storage.

Another factor in satisfactory terminal response is the communications element. A MODCOMP minicomputer interfaces the CDC-6600 with over 80 dial-up lines. Data rates of 10,30 , and 120 characters per second are provided. The time-sharing facility has capacity for more lines and higher data rates as the need arises.

\section{Current Equipment}

Computer Model or Feature

CDC-6600

Main memory

Swapping storage

Disk storage

Remote terminal lines

*Word size is 60 bits.

At Livermore, time-sharing access to one of the CDC6600 's is provided by a network of graphic and alphanumeric terminals connẹcted via hardwired lines. The terminals are all located within the security area and may be used for classified processing. Over 20 terminals are currently available, with a maximum capacity of 32 lowspeed ( 4800 baud) and four high-speed ( 40.8 kilobaud) ports. Terminal users have access to most of the same processors and system utilities as batch users, in addition to services necessary for support of interactive terminals.

\section{Programming Languages and Special Processors}

The languages, special processors, and utilities supported on these time-sharing facilities reflect the breadth of applications amenable to interactive computation. Only a small subset of the software tools available is noted here. Typically, time-sharing systems are rich in supporting software. This is necessary because of the high degree of man-machine interaction involved. Thus, emphasis is placed on testing aids, editors, file manipulation and retrieval capabilities, etc.

Currently Supported Languages and

Nationally Known Software Processors

Assemblers and compilers
COMPASS
BASIC
FORTRAN extended
COBOL
APL
SYMPL
PASCAL
SNOBOL

Miscellaneous cross assemblers, compilers, and simulators for minicomputers. 
Testing tools, editors, and maintenance packages XEDIT

TECO

UPDATE

MODIFY

TIDY

Mathematical libraries

Sandia mathematical program library

IMSL

Electronic circuit analysis

ITRAC

ECAP

Document prejáa alium

RUNOFF

Graphical Plotting

DISSPLA

PLOT-10

SCORS

GCS

\section{Applicatinns}

The time-sharing systems service a large number of users, including those only occasionally or minimally involved in computation per se. The spectrum of applica- tions is quite broad, ranging from theoretical modeling to engineering applications to test operation scheduling and quality control. Excluded are large-scale computationbound codes. This restriction ensures adequate system response for jobs that are appropriate for a time-sharing environment. In any case, the systems are used primarily for scientific and engineering applications requiring rapid turnaround and direct interactive control. Some of these applications are of a one-time nature. The time-sharing computer in such instances represents an extension of the enyineer's standard calciulating tools. Other applications require the continuted use of codes and the maintenance of data bases over extended periuds of time.

A brief summary of application areas is as follows:

Engineering and scientific calculations

Cross compiling of codes for various dedicated minicomputers

Simulation of continuous systems

Closed-form equation solution; i.e., symubul inanluulation

Technical document preparation and updating

File maintenance and inquiry applications; i.e., test operation center scheduling, measurement standards files, etc. 


\section{INTERACTIVE GRAPHICS FACILITIES}

Interactive graphics is a computational capability provided for applications requiring on-line decision-making based on a dynamic, visual depiction of the processes under consideration. Typical applications include network design, circuit layout, trajectory analysis, system simulations, and data fitting. The Laboratories' primary emphasis in the interactive graphics area is directed toward high-performance systems that provide a variety of graphical input and display devices, and afford maximum flexibility in interactive control. Satellite computer/controllers manage these interactive, refresh-scope-based facilities and provide the necessary interface to the larger centralized systems (CDC-6600's). Primary computation is done in the latter systems, and the-results (display files, data arrays) are transmitted to the graphics satellites. Complementing the high-performance systems is an increasing number of storage-tube graphics terminals linked directly to the central facilities in Livermore or Albuquerque. In Albuquerque these terminals are supported on the timesharing system via dial-up access.

In addition to the central facility-supported systems, several essentially autonomous interactive units are in operation. These include three APPLICON-875's used for machineaided design definition. In addition, Sandia's CDC-6400 data-reduction computer (discussed in a following section) supports two high-precision CDC-777 graphics terminals.

\section{Graphics Satellite Stations}

The Livermore facility contains two high-performance CDC-777 graphics stations. These consoles are controlled by a CDC System 17 minicomputer which, in turn, is connected to the Livermore time-sharing CDC-6600 over a hardwired high-speed (40.8 kilobaud) communications link. These stations provide a refresh-type scope display and interactive control that functions under a standard CDC operating system. In addition, the central facility supports a mediumscale Tektronix- 4081 graphics station with a limited refresh mode capability, and a number of direct-view storage tube (DVST) terminals. The Albuquerque center also supports a host of DVST terminals and two Tektronix-4081's.

The high-performance graphics complex in Albuquerque is collectively known as the SIGS (Sandia Interactive Graphics System). SIGS consists of six satellite computers (five PDP-9's and one PDP-15), each with a Vector General interactive display. Orie of these satellites supports a COMTAL 8300 image processor unit for generating continuous-tone graphics. The satellite computers, in turn, are connected to a single CDC-6600 computer via a high-speed synchronous communication link. These links are controlled by a MODCOMP II computer. The software for this communication subsystem, designed at Sandia, permits the concurrent servicing of each remote station. Each satellite is capable of stand-alone operation with its full complement of local peripherals (disk storage, printer, card reader, tapes, etc.). Most computations, however, are accomplished in the host CDC-6600 system. A typical application would require programming at both the CDC-6600 and satellite ends. This Sandia-developed interactive graphics system is unique, both in hardware and software; therefore, it is not compatible with similar subsystems developed by Control Data Corporation. (Item 1)*

\footnotetext{
"See Highlights, below.
} 
Standard Equipment on Each of the Six

Satellite Graphics Computers (Albuquerque)

$\begin{array}{lc}\text { Component or Feature } & \text { Number or Capacity } \\ \text { Main memory size } & 24,000 \text { words* } \\ \text { Disk storage } & 524,000 \text { words * } \\ \text { DEC tape transports } & 2 \\ \text { Electrostatic printer/plotter } & 1 \\ \text { Card reader } & 1 \\ \text { Teletype console } & 1 \\ \text { Direct view storage tube } & 1 \\ \text { Vector General display console } & 1 \\ \text { Graphics input devices: } & \\ \quad \text { Keyboard } & 1 \\ \text { Light pen } & 1 \\ \text { Data tablct } & 1 \\ \text { Control dials } & 10 \\ \text { Features: } & \\ \text { 21-inch refresh scope } & \\ \text { Hardware rotation } & \\ \text { Three-dimensional Vector } & \text { representation } \\ \text { Depth cueing } & \\ \text { Hardware scissoring } & \\ \text { Display subroutining } & \end{array}$

*Word size is 18 bits.

\section{Applications}

Applications in which the existing interactive graphics facilities are used vary considerably and represent a growing spectrum of activities. The common thread, however, is the need to incorporate the human decision-making element into the computation process in an iterative manner. The best applications are those in which graphical portrayal of the problem plays an essential role in its solution.

\section{Currertl Applications}

Printed circuit board layout
Circuit design and analysis
Integrated circuit mask generation
Alrcraft/store-separatıon analysis
Source/sink aerodynamic model calculations
Stability analysis of linear systems
Post-processing graphical analysis of
hydrocode calculations
Generalized curve fitting
Data reduction
Mesh generation for large Lagrangian codes
Digital logic simulation
Material-strength modeling
Topographical analysis for guidance system
$\quad$ design
Solar collector simulation

Printed circuit board layout

Circuit design and analysis Alrcraft/store-separation analysis

Source/sink aerodynamic model calculations

Stability analysis of linear systems

Post-processing graphical analysis of

Data reduction

Mesh generation for large Lagrangian codes

Digital logic simulation

Material-strength modeling

Solar collector simulation

\section{Item 1. Interactive Graphics Codes}

Of the various interactive graphics codes developed, two deserve special mention for their extent of application and their relative impact. DAVINCI is an interactive program that allows the layout and updating of printed circuit boards. Basic DAVINCI options selected by a lightpen allow the user to display various combinations of circuit layers. The pictures can be enlarged by a software window option to permit examination of areas in closer detail. Clearance for electrical standoff is an important design parameter. The system provides visual arid andalytical checking methods. Manipulation capabilities allow parts to be added, deleted, revised, or duplicated. The final results are outputted in a manner suitable for generating artwork masters on automatic drafting machines, or alternatively for driving numerical-control machines. 


\section{INTERACTIVE GRAPHICS FACILITIES}

The second code, GAIN, provides an interactive capability for defining network topologies in schematic form. The circuit descriptions, in turn, are transferred to an interactive version of SCEPTRE which computes and displays the response characteristics of the circuits so defined. This combination provides the designer with an iterative, human-oriented computational capability that expedites the design process.

Both GAIN/SCEPTRE and DAVINCI were developed for use on the SIGS graphics system. Figure 1 demonstrates the use of the latter code.

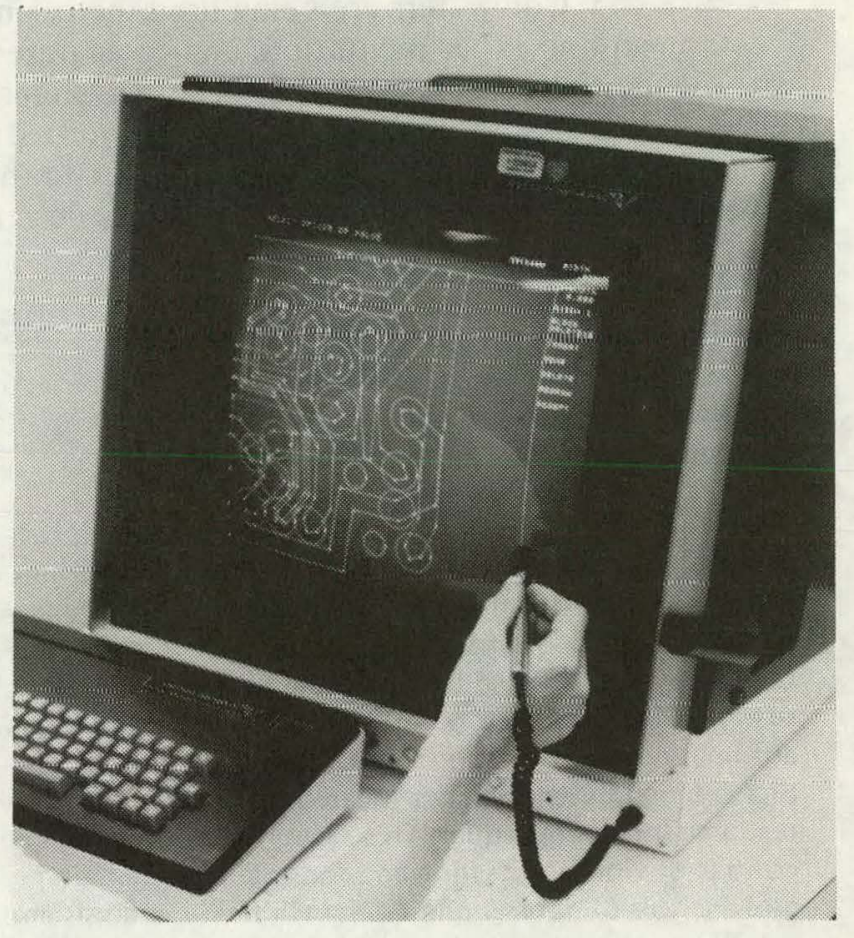

Figure 1. The DAVINCI code being used on the Sandia Interactive Graphics System 


\section{COMPUTER-BASED SPECIAL-PURPOSE SYSTEMS AND SUPPORT}

Computers are being used increasingly to control laboratory equipment, to assist in on-line experimentation, and to acquire data. Following are examples of some of our major computer-based special-purpose systems. In each case a computer is integrated into a larger system and provides the critical control and processing required. Such computers, although usually general-purpose in nature, are thus essentially dedicated to the specific applications for which the system as a whole is designed.

\section{Instrumentation and Data Systems}

Four major computer systems are included in this category. Most final reduction of data from the various test sites is done on the CDC- 6400 computer in Albuquerque. Telemetry, optical, radar, and various instrumentation data are processed by that facility. Playback is by an off-line CDC-3100 computer. Other facilities include an automatic data-processing system based on an XDS Sigma- 5 computer, which is located in the environmental test area in Albuquerque. This system is used for on-line control of vibration testing and for post-test digitizing and analysis of data. Following preliminary analysis and validity testing, the results are often transmitted to the CDC-6400 for final processing.

Tlı same relationshıp with respect to the CDC-6400 holds for the DITAC system at the Tonopah Test Range. DITAC is an advanced real-time digital acquisition and plotting system engineered around a pair of Honeywell DDP-124 computers. In addition to its data-gathering function, DITAC controls the automatic positioning of cinetheodolites, tracking telescopes, and radar instrumentation. DITAC also handles the automatic focusing of optical instrumentation, and provides real-time target trajectory data to digital plotting boards and visual displays.

A data playback and digitizing system, built around an XDS-930 computer, also exists at Livermore. (Item $1^{*}$ )

\section{Current Activities}

Development of user-oriented data-reduction system

Development of time-sharing technique for managing telemetry data base

\section{Flight-Simulation Facilities}

Analog and hybrid computer equipment is used to perform real-time flight simulations. In some instances,

\footnotetext{
*See Highlights, below.
}

actual guidance-and-control hardware is incorporated into the data loop for more realistic simulation. These facilities play an important role in the development of stand-off missiles, reentry vehicles, shells, and rockets. The four facilities dedicated to flight simulation work include three AD/FIVE's interfaced to a PDP-11/45; an EAI-7800 interfaced to an EAIPACER; an EAI-580 and TR-48 interfaced to a NOVA-800; and an EAI-680. Each of the first two facilities includes a Carco three-axis angular-motion simulator interfaced to the hybrid computer equipment. Hardware may be mounted on the Carco device and subjected to the angular velocities and accelerations actually experienced in full-scale flight. (Item 2)

\section{Current Activities}

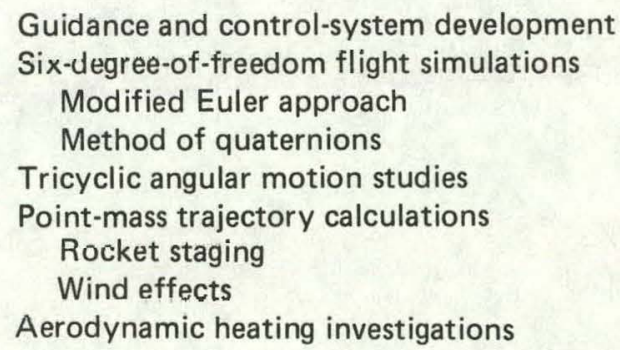

Microelectronics Laboratory System

A dedicatcd compuler system is used to control laboratory experiments involving semiconductor devices, and to perform high-speed data-acquisition and reduction on a real-time basis. The central computer is presently a Varian 72 with 144,000 words ( 16 bits each) of core memory, 36 million words of disk storage, and various peripheral devices. Linked remotely to this computer are a number of Hewlett Packard minicomputers which in turn control semiconductor device testers and equipment in the Semiconductor Development Laboratory. Data from the testers are processed, and summary information is plotted on graphics display stations in remote laboratories. The automated station provides the design engineer and the laboratory experimenter with processed experimental information on a real-time basis. (Item 3 ) 


\section{COMPUTER-BASED SPECIAL-PURPOSE SYSTEMS AND SUPPORT}

\section{Current Activities}

Testing of device characteristics

Current versus applied voltage

Capacitance-voltage characteristics

Time-dependent effects

Microwave transistor S-parameters

Measuring wafer characteristics

Circuit characteristics

Sheet resistivity

Impurity concentrations

Lifetime values

Evaluation of fabrication processes

Automatic equipment control

Accurate device/wafer records

\section{Numerical Control Facility}

A PDP-15 computer generates machine-tool programming instructions used to control machinery in the fabrication shops. Direct data transfer from computer to machine reduces lead time and practically eliminates wait time for program changes and program optimization. A link from the PDP-15 to the UNIVAC-1108 at the central computing facility permits the processing of computing jobs that exceed the capacity of the PDP-15.

\section{Current Activities}

Real-time system programming

Numerical-control part programming

Tool application programming

Computer interface design

\section{Electrui-Beam Fusion Data Acquisition Facility}

A MODCOMP $11 / 25$ computer system is used to acquire and process data from the e-beam fusion research accelerators Hydra, Proto I, and Proto II. The central processing unit contains 65,00016 -bit words of core memory plus hardware floating point. Peripherals include two cartridge moving-head disks, two 7-track tap drives, two Tektronix 4010-1 computer display terminals, and a hard-copy unit. The real-time multi-task capabilities of the Mlax III operating system are use extensively.

Data are acquired on-line via 15 Tektronix 7912 transient digitizers. The computer performs a diagnostic check for each 7912 before each shot. It then arms the digitizers and acquires data after the shot. Input signals are automatically routed from the accelerator in use to the 7912's via a computer-controlled coaxial switching matrix. All data are displayed in graphic form on the 4010 terminals. The software is written to allow two independent users to nperate simultaneously, one on each terminal.
Data are also acquired off-line via conventional oscilloscope photography. The photographs are then digitized by a Colorado Video $\mathbf{2 7 0}$ digitizer incorporated into a closed-circuit television system and interfaced to the computer. Data produced by the video digitizer are handled in the computer in the same way as data produced by the 7912 's.

\section{Current Activities}

Monitoring accelerator diode voltage $[\mathrm{V},(\mathrm{dV} / \mathrm{dt})]$ and current $[\mathrm{l},(\mathrm{dl} / \mathrm{dt})]$ waveforms for all three machines.

Computing diode impedance, power, and energy from voltage and current inputs.

Monitoring diode $x$-ray output with pin diode detectors.

Monitoring neutron output on target shots.

Deconvolving out cable high-frequency rolloff effects from all input signals.

Five-Megawatt Solar Thermal Test Facility

A network of 9 minicomputers is used to control a field of approximately 78 sun-tracking mirrors (heliostats). The primary computer-controlled functions are control of the steam and heat rejection subsystems, data gathering, and control of the experiments under test. Five MODCOMP II 25's are used for mirror control: Hewlett Packard $21 \mathrm{MX}$ 's are used for weather data, experiment data, solar flux calibration, and the supervisory functions of operator interface, real-time data presentation, and network management. Experimental steam boilers for electric power generation are tested at the facility, as well as other sur-puvered devices. In addition, experiments are conducted which facilitate the investigation of photovoltaic devices and high-temperature metallurgy research. A dual-monitor color graphic console is incorporated into the controls, eliminating the large control boards usually required in a generating plant, and allowing real-time data display and operator modification of the test.

\section{Current Activities}

Heliostat testing

Development of reflected energy datacalibration techniques

Development of human-engineered, operatororiented control methods

Investigation of safety problems in using reflected solar energy

Development of real-time data analysis and display techniques. 


\section{Item 1. User-Oriented Data-Reduction Facility}

A major new data-playback/data-reduction system has been funded and is under development. The facility will consist of a state-of-the-art automated telemetry "front-end" coupled to thie CDC-6400 mentioned earlier. With the addition of a major on-line graphics capability, the system will permit users to "interact" with their data and control the reduction process via CRT consoles. Turnaround time for field-test data reduction is expected to be substantially improved. Figure 1 is a schematic of the playback/data-reduction facility.

\section{Item 2. Rocket Stability Analysis}

The AD/FIVE-PDP $11 / 45$ hybrid computer shown in Figure 2 was used in the flight-stability analysis of the Nike-Malemute sounding-rocket systcm. Causes of excessive angular motion observed in the flight of the second-stage Malemute were traced to certain high-order aerodynamic forces and moments acting normal to the plane of incidence. The analysis indicated the type of configurational changes required to obtain satistactory flight characteristics.

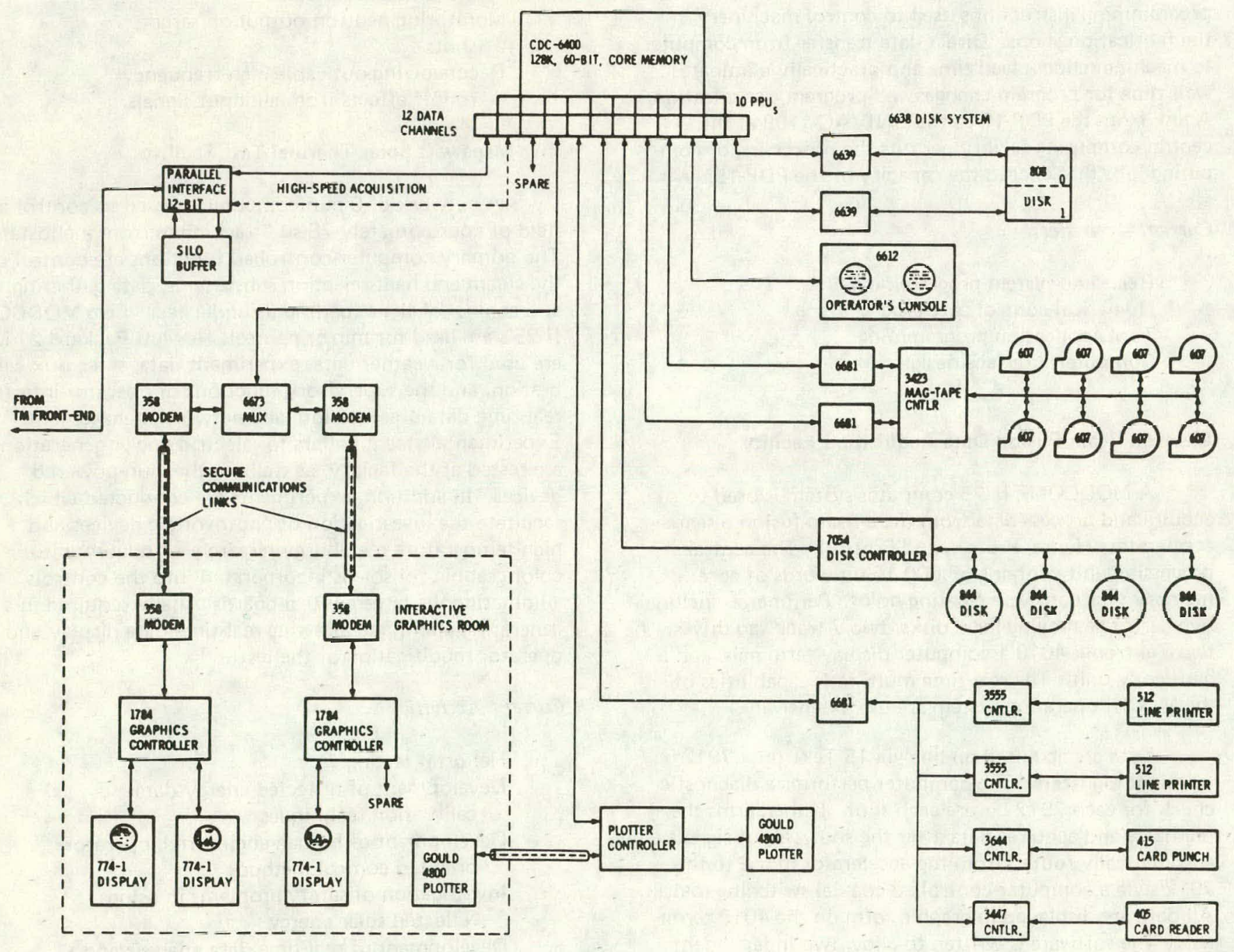

Figure 1. Central computer user-oriented data reduction system 


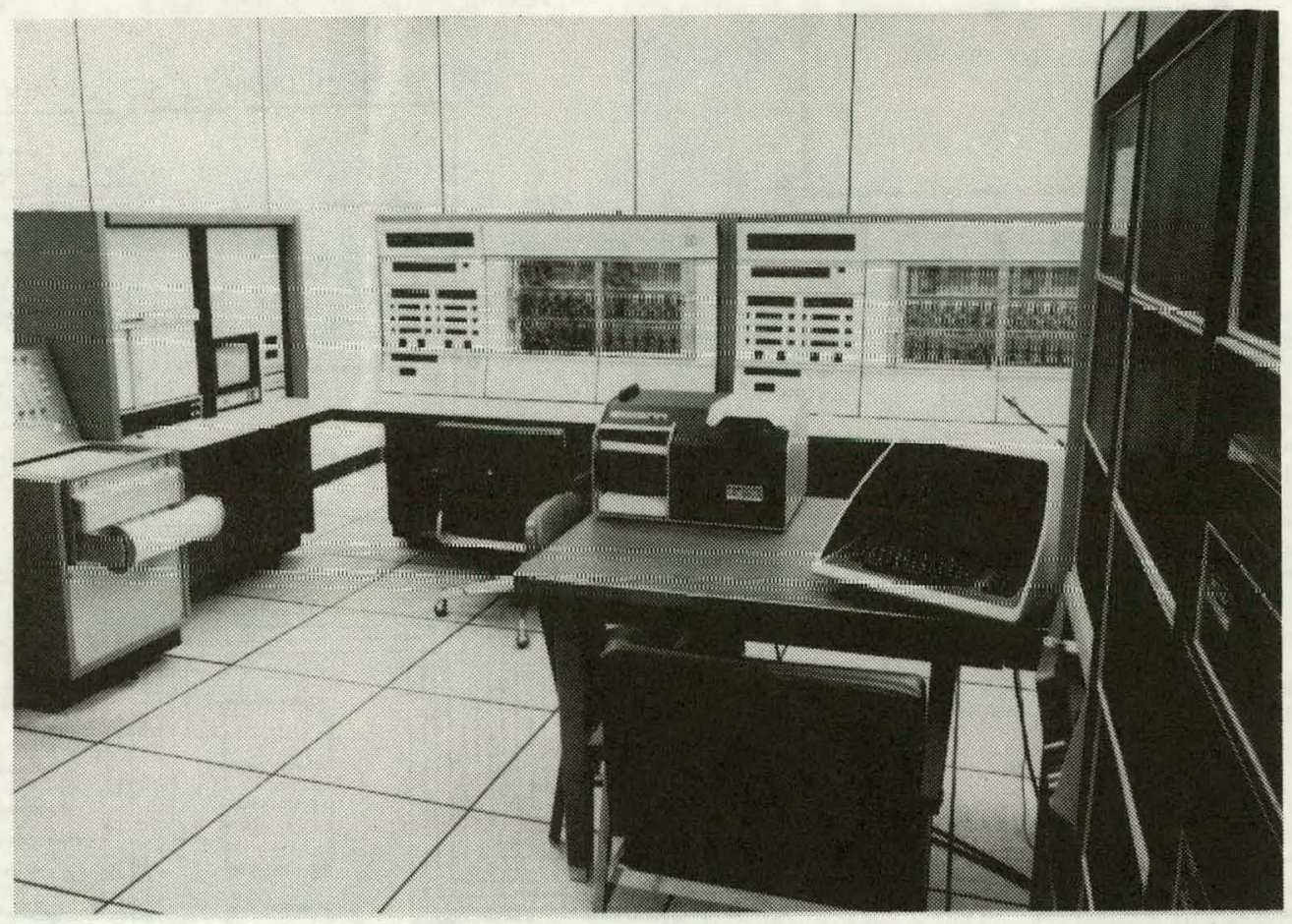

Figure 2. The AD/FIVE-PDP $11 / 45$ hybrid computer

\section{Item 3. Microelectronics Laboratory Computer Development}

A new microelectronics laboratory has been constructed that is capable of producing silicon semiconductor devices ranging from discrete devices to medium and largescale integrated circuits containing thousands of transistors. To support this effort, a program has been implemented for the computer-aided design of circuit masks. In addition, computer codes are being used for circuit analysis and simulation studies bearing on the design of complex integrated circuits.
A sixth SIGS graphics station has been installed to support the growing computational load in this area. Moreover, the previously described microelectronics computer facility provides additional services such as monitoring and control of diffusion furnaces, ion implantation and wafer probing equipment, and radiation-effects testing. This data-acquisition and laboratory control computer is depicted schematically in Figure 3. 


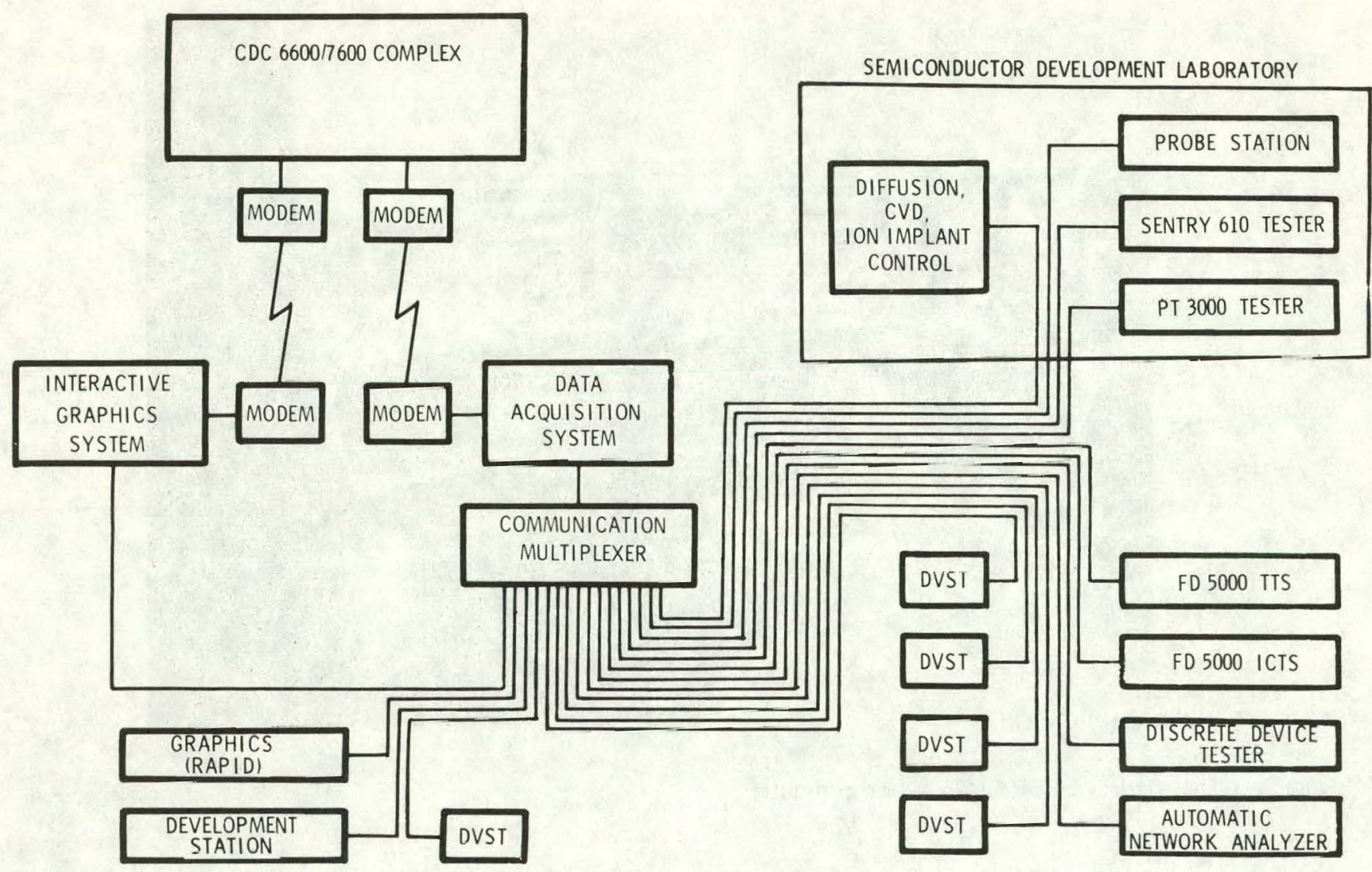

Figure 3. Microelectronics data acquisition system 


\section{SUMMARY OF MAJOR COMPUTATION SYSTEM FACILITIES}

SCIENTIFIC COMPUTERS. Networks of large-scale computers at Albuquerque and at Livermore are used for solving problems in the areas of weapon design, component development, energy research, reactor and nuclear safety, effects modeling, and test-data reduction. These centralized facilities presently include a C.DC-7600, five C.DC-6600's, and a C.YBL:R-172.

MASS STORAGE. Both centers support large-capacity magnetic-disk subsystems for the storage of data and program files. These are backed up by an extensive magnetic tape library.

REMOTE TERMINALS. Within the various facilities, remote batch terminals provide a direct link to central computers. In addition, a large number of teletype-like portable terminals permit access to the respective computer centers via dial-up or hardwired lines. A growing number of medium-scale and high-performance graphics stations provide interactive graphics capability for on-line design.

COMPUTER OUTPUT MICROFILM FACILITIES. An important capacity exists for placing computer-generated graphical and tabular information onto microfilm $(16 \mathrm{~mm}, 35 \mathrm{~mm}$, microfiche). Savings accrue in both media and storage costs. Moreover, particularly in complex simulations of time-dependent physical processes, the cinema-graphical depiction of results is the optimal approach to understanding the phenomena involved. Both.black/white and color film are generated.

INPUT/OUTPUT PERIPHERALS. Printers, card readers, tape drives, and other input/output devices provide a futidamental capability to the computing networks, both onsite and at remote entry terminals. 
DISTRIBUTION:

Commander

Air Force Weapons Laboratory

Kirtland AFB, New Mexico 87117

Attn: D. E. Mclntyre

Los Alamos Scientific Laboratory (2)

Attn: Report Librarian

P. O. Box 1663

Los Alamos, New Mexico 87544

Attn: W. J. Worlton, C-DO

C. A. Folkner, C-DO

2600

2601

2610

2611

2612

2613

2614

2620

2625

2826

2627

2628

2630

2631
L. E. Hollingsworth
E. M. Brault
R. J. Detry
M. B. Moore
D. A. Young
M. R. Scott
G. D. Horne
A. J. Arenholz
C. R. Andes
W. A. Gardner
E. C. Dommie
E. G. Thuman
E. K. Montoya
J. E. Wesbrook

2632

2633

2635

2640

2641

2643

2644

2647

2648

3433

3151

3162

4010

8320

8321

8323

8324

8325

8326

8327

8266

3141

3151

DOE/TIC (25)

K. O. Waibel

D. E. Robertson

D. H. Emrick

J. L. Tischhauser

P. A. Lemke

B. T. Fox

A. R. lacoletti (50)

D. C. Jones

D. H. Schoeder

E. M. Moore (50)

P. L. Mead

J. M. Pollto

C. D. Lundergan

T. S. Gold

R. L. Rinne

A. G. Schuknecht

G. S. Brown

R. E. Huddleston

J. P. Eiker

R. Y. Kee Jr.

E. A. Aas

C. A. Pepmueller (Actg) (100)

W. L. Garner (3)

For DOE/TIC (Unlimited Release)

(R. P. Campbell, 3172-3) 